\title{
Can ENSO-Like Convection Force an ENSO-Like Extratropical Response on Subseasonal Time Scales? 0
}

\author{
Michael Goss \\ Department of Meteorology, The Pennsylvania State University, University Park, Pennsylvania, and Department \\ of Earth System Science, Stanford University, Stanford, California \\ SuKyoung LeE AND STEVEn B. FeLdSTEIN \\ Department of Meteorology, The Pennsylvania State University, University Park, Pennsylvania
}

NOAH S. DifFENBAUGH

Department of Earth System Science, and Woods Institute for the Environment, Stanford University, Stanford, California

(Manuscript received 11 November 2017, in final form 7 May 2018)

\begin{abstract}
A daily El Niño-Southern Oscillation (ENSO) index is developed based on precipitation rate and is used to investigate subseasonal time-scale extratropical circulation anomalies associated with ENSO-like convective heating. The index, referred to as the El Niño precipitation index (ENPI), is anomalously positive when there is El Niño-like convection. Conversely, the ENPI is anomalously negative when there is La Niña-like convection. It is found that when precipitation becomes El Niño-like (La Niña-like) on subseasonal time scales, the 300-hPa geopotential height field over the North Pacific and western North America becomes El Niñolike (La Niña-like) within 5-10 days. The composites show a small association with the MJO. These results are supported by previous modeling studies, which show that the response over the North Pacific and western North America to an equatorial Pacific heating anomaly occurs within about one week. This suggests that the mean seasonal extratropical response to El Niño (La Niña) may in effect simply be the average of the subseasonal response to subseasonally varying El Niño-like (La Niña-like) convective heating. Implications for subseasonal to seasonal forecasting are discussed.
\end{abstract}

\section{Introduction}

El Niño-Southern Oscillation (ENSO) is a tropical mode of variability typically defined by sea surface temperature (SST) anomalies in the central and eastern equatorial Pacific Ocean (e.g., Trenberth 1997; Hanley et al. 2003). Warm SST anomalies over the region are associated with enhanced convective precipitation, enhanced upward vertical velocities, and an associated weakening or reversal of the Walker circulation, which typically has a downward branch over the eastern equatorial Pacific

\footnotetext{
Supplemental information related to this paper is available at the Journals Online website: https://doi.org/10.1175/JCLI-D17-0771.s1.
}

Corresponding author: Michael Goss, goss@stanford.edu
Ocean (Julian and Chervin 1978; Rasmusson and Wallace 1983). Likewise, cold SST anomalies over the region are associated with suppressed convective precipitation, enhanced downward vertical velocities, and a strengthening of the Walker circulation. Typically, an "El Niño" is defined when SST anomalies exceed a particular threshold value over interseasonal or interannual time scales, and a "La Niña" is defined when SST anomalies fall below the negative of the same threshold value for the same time scales (Trenberth 1997).

Because ENSO is by definition an interseasonal to interannual phenomenon, it is typical to examine the impacts over the midlatitudes on these time scales. However, studies such as those of Chiodi and Harrison $(2013,2015)$ and Johnson and Kosaka (2016) identify the strong sensitivity of the midlatitude response to the specific location of the convective precipitation anomalies during El Niño, 
illustrating the importance of short time-scale convection in driving the midlatitude response to ENSO. Specifically, Chiodi and Harrison (2015) show that the midlatitude impacts associated with ENSO are very sensitive to the specific spatial structure of OLR anomalies, suggesting that variations in convection during different ENSO events modulate the response. In general, changes to the tropical atmospheric circulation associated with the regions of enhanced or suppressed convection during El Niño or La Niña, respectively, have wide-ranging impacts on the midlatitudes (e.g., Ropelewski and Halpert 1986; Lau 1997; Alexander et al. 2002) and even the high latitudes (Gloersen 1995; Jevrejeva et al. 2003; Liu et al. 2004; Goss et al. 2016), especially in the winter hemisphere. These effects are seen strongly over the North Pacific and North America in El Niño or La Niña composite geopotential height anomalies (Ropelewski and Halpert 1986; Zhang et al. 1996; Trenberth et al. 1998). Additionally, there are other equatorial phenomena that affect tropical precipitation and the tropical circulation, such as the Madden-Julian oscillation (MJO), which occur on subseasonal time scales (Madden and Julian 1971; Wheeler and Hendon 2004). Like ENSO, these phenomena also affect the mid- and high-latitude circulation patterns. The MJO, for example, induces a geopotential height response over the North Pacific and North America (Mori and Watanabe 2008; Johnson and Feldstein 2010; Yoo et al. 2012a; Goss and Feldstein 2017).

In a previous study, Goss and Feldstein (2017) examined the similarities and differences between the ENSO and MJO responses in the context of the tropical precipitation patterns. They found that differences in the geopotential height response between ENSO and a similar-looking MJO precipitation pattern are associated mostly with differences in the relative amplitude of the precipitation anomalies over the western Pacific warm pool (WP) versus the central Pacific (CP). In fact, during a typical ENSO or MJO, oppositesigned WP and CP precipitation anomalies induce opposite-signed geopotential height anomalies over the North Pacific and North America, causing some cancellation in the impacts over those regions (Goss and Feldstein 2018). Ultimately, they found that the MJO (ENSO) response most closely resembles the response to isolated WP (CP) convection.

Although the low-frequency (interseasonal to interannual) response to ENSO is associated with SST variability via enhancement or suppression of convection, various modeling and observational studies show that the North Pacific and North American response to a general convective heating anomaly over the equatorial Pacific tends to occur within about 7-10 days (e.g., Hoskins and Karoly 1981; Yoo et al. 2012a,b). Additionally, convection anomalies during ENSO can vary on subseasonal time scales in association with the MJO and other phenomena, which modulate the equatorial precipitation and tropical circulation pattern in ways that can either diminish or enhance the canonical ENSO convection field. Johnson and Kosaka (2016) showed that during El Niño, the response to subseasonal-scale enhanced convection anomalies over the central and eastern equatorial Pacific drives an extratropical response on the same time scales. This implies that the physical mechanisms driving the midlatitude response are the same for a general heating anomaly as they are for one induced by ENSO, regardless of the source of an El Niño-like or La Niña-like heating/precipitation anomaly over the CP. Therefore, we would expect the midlatitude response to general El Niño-like or La Niñalike convection to also occur within about 7-10 days.

The aim of this study, then, is to address the following four questions using observational data: 1) Do there exist times when precipitation anomalies over the tropics become significantly more El Niño-like or La Niña-like over subseasonal time scales? 2) If so, do we see an associated El Niño-like or La Niña-like geopotential height response over the North Pacific and North America? 3) How long after the tropical forcing does the extratropical response occur? 4) What does the subseasonal response to El Niñolike or La Niña-like convection imply about the seasonal response to El Niño or La Niña?

Section 2 describes the methods and data used in this study. Section 3 presents the results of the study. Section 4 discusses how the results address the four questions presented above.

\section{Methods and data}

For much of this study, we employ a lagged composite analysis. Daily fields for several variables from the European Centre for Medium-Range Weather Forecasts interim reanalysis (ERA-Interim; Dee et al. 2011) are obtained on a fixed grid with a horizontal grid spacing of $1.5^{\circ}$ for the period $1979-2013$. We specifically retrieve the daily $300-\mathrm{hPa}$ geopotential height fields, since the midlatitude upper troposphere is most strongly influenced by equatorial convection. Precipitation data are from the National Oceanographic and Atmospheric Administration (NOAA), specifically the Climate Prediction Center Merged Analysis of Precipitation (CMAP; Xie and Arkin 1997). ${ }^{1}$ These data consist of pentadal precipitation rates on a fixed grid with a horizontal grid spacing of $2.5^{\circ}$. We

\footnotetext{
${ }^{1}$ We performed identical calculations using the Earth System Research Laboratory's Global Precipitation Climatology Project (GPCP) dataset, also from NOAA. We found that the results were broadly similar, although the response to La Niña precipitation was less robust for 30 events. With 45 or more events, the La Niña response more closely matches the CMAP results.
} 
have retrieved daily values by linearly interpolating the pentadal data.

For the purposes of this study, we calculate the climatology of each variable as a smoothed annual cycle. At each grid point, we calculate the average value of each variable over all 35 years separately for each day of the year (DOY). We then smooth these annual cycles by only retaining the first 10 harmonics, using a Fourier transform. The anomalies are calculated based on the resulting climatology, by subtracting from the total daily field the climatology for the corresponding DOY. In this manuscript, we use "climatology" to represent the smoothed annual cycle, and "anomaly" to represent the deviation from this cycle.

We seek a measure of ENSO-like convection that can capture subseasonal variability, meaning that traditional measures of ENSO such as the Niño-3.4 SST are insufficient. Using precipitation data, we derive a daily index for El Niño-like precipitation, which we call the El Niño precipitation index (ENPI). The results in Goss and Feldstein $(2017,2018)$ indicate that we would expect to see the most amplified response over the North Pacific and North America when anomalous precipitation over the central equatorial Pacific is amplified, but anomalous precipitation over the warm pool region is closer to neutral. For this reason, we would like to find times when these criteria hold. Therefore, we first subdivide the equatorial Pacific into two sectors: the central Pacific sector, which extends from $15^{\circ} \mathrm{S}$ to $10^{\circ} \mathrm{N}$, and from $165^{\circ} \mathrm{E}$ to $120^{\circ} \mathrm{W}$, and the warm pool sector, which extends from $15^{\circ} \mathrm{S}$ to $15^{\circ} \mathrm{N}$, and from $90^{\circ} \mathrm{E}$ to $150^{\circ} \mathrm{E}$. These are regions where the sign does not tend to vary in the El Niño/La Niña precipitation anomaly composites (see Fig. 3, described below).

We define the daily ENPI time series using (1) below:

$$
\mathrm{ENPI}=P_{\mathrm{CP}} \frac{\left|P_{\mathrm{CP}}\right|}{\left|P_{\mathrm{CP}}\right|+\left|P_{\mathrm{WP}}\right|} .
$$

Here, $P_{\mathrm{CP}}$ represents the spatially averaged precipitation anomaly over the $\mathrm{CP}$ region, and $P_{\mathrm{WP}}$ represents the spatially averaged precipitation anomaly over the WP region. The first term in (1) varies with the strength and sign of the CP precipitation anomaly. The second term in (1) is a fraction ranging from 0 to 1 , which represents the strength of the $\mathrm{CP}$ anomaly relative to the WP anomaly. Values for the second term that are closer to 0 represent much stronger WP anomalies, and values that are closer to 1 represent much stronger CP anomalies. Since the absolute value of CP anomalies is usually much larger than that for WP anomalies for both El Niño and La Niña, large positive values of ENPI correspond to $\mathrm{El}$ Niño-like precipitation and large negative values of ENPI to La Niña-like precipitation.
Although we believe the ENPI definition used here is justified based on the reasoning given above, we additionally tested the sensitivity of the results to other definitions of the ENPI. Specifically, we used a definition where the western boundary of the CP domain extends westward to $150^{\circ} \mathrm{E}$, but was otherwise identical. Additionally, we used a definition where $P_{\mathrm{WP}}$ was ignored, so that the ENPI definition only depends on CP precipitation. The corresponding figures can be seen as Figs. S1-S6 in the online supplemental material. Both of these definitions, compared with our preferred definition, produced convective features that were less conducive to generating a clean El Niño-like or La Niña-like height response, as borne out in the resulting composite height fields, which we believe further supports the use of our preferred ENPI definition.

To illustrate how the ENPI compares to more traditional measures of ENSO, we plot three histograms of Niño-3.4 SST values (linearly interpolated from a monthly index to a daily index), seen in Fig. 1. First, we show those DJF Niño-3.4 values during which the ENPI is greater than 1.0, corresponding to El Niño-like convection (Fig. 1, red). We next show DJF Niño-3.4 values during which the ENPI is less than -1.0, corresponding to La Niña-like convection (Fig. 1, blue). Finally, we show DJF Niño-3.4 values during which the ENPI is between -1.0 and 1.0, corresponding to neutral convection (Fig. 1, green). We see that, in general, the Niño3.4 values are consistent with the ENPI values, with mostly positive Niño-3.4 values when the ENPI is positive, mostly negative Niño-3.4 values when the ENPI is negative, and mostly near-zero Niño-3.4 values when the ENPI is close to zero. However, there is some variation, and rarely the Niño-3.4 values may be below 0 with El Niño-like convection or above 0 with La Niña-like convection. Nevertheless, we see that the ENPI generally matches the state of the SST anomalies.

We are interested in analyzing periods when the ENPI peaks on subseasonal time scales, in order to test whether the circulation response over the North Pacific and North America follows 7-10 days later. To find these periods, the days on which we base our lagged composite analysis are determined as follows. First, we calculate a filtered ENPI $\left(\mathrm{ENPI}_{\mathrm{HP}}\right)$ by applying a 40-day high-pass filter to the daily ENPI time series. ${ }^{2}$ We only consider DJF days when the ENPI value is greater than 0 . The highest $\mathrm{ENPI}_{\mathrm{HP}}$ value during those days is considered the first event. Then, prior

\footnotetext{
${ }^{2}$ A 40-day high-pass filtering period is chosen to capture variability only on subseasonal time scales. Our results are not sensitive to choices of high-pass filtering periods ranging from 30 to at least 90 days. We also note that a weaker subseasonal signal appears even when we perform the analysis with unfiltered ENPI data.
} 


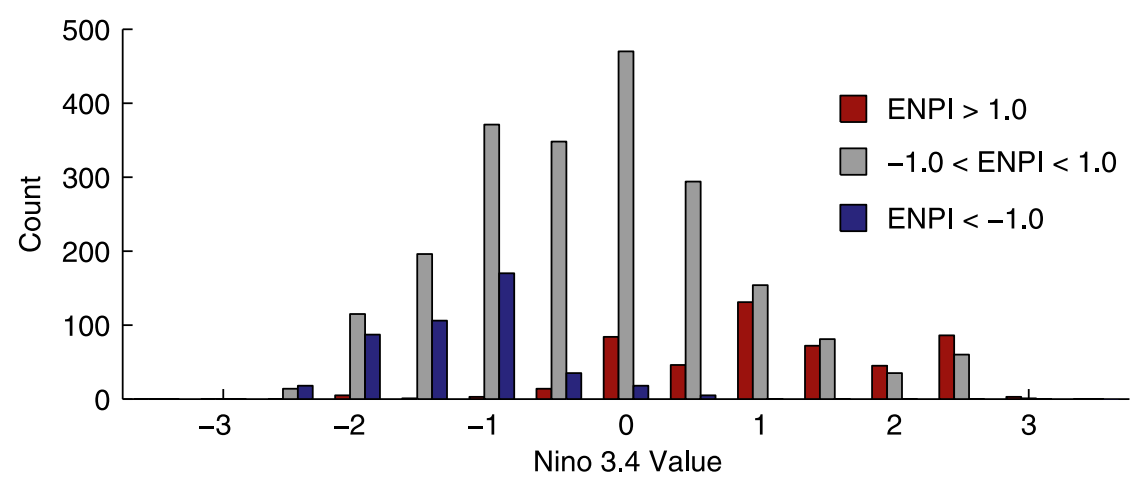

FIG. 1. Histogram of Niño-3.4 values for DJF days when the ENPI value is greater than 1.0 (red), between -1.0 and 1.0 (gray), and less than -1.0 (blue).

to searching for the next event, we discard the 10 consecutive days before and the 10 consecutive days after that day. The second event is then found by checking for the highest $\mathrm{ENPI}_{\mathrm{HP}}$ value from the remaining pool, with the 10 days before and 10 days after discarded once again. This process is repeated until 30 events are identified. ${ }^{3}$ For La Niña-based events, we use an analogous method, choosing only DJF days where the ENPI value is less than 0 , and basing the choice of events on the most negative values of the ENPI $\mathrm{HP}_{\mathrm{H}}$.

An example of this process for La Niña events for the winter of 2000/01 is shown in Fig. 2. The diamonds correspond to the first two events that would be chosen from that period alone, with the numbers corresponding to the order the events are chosen. Thick lines in both panels correspond to times when the ENPI value is less than the 0 threshold value. The top panel is the ENPI for the winter, and the bottom panel is the ENPI $\mathrm{HP}_{\mathrm{HP}}$ for the same time period. The green windows correspond to the 10 days on each side that are blocked from consideration for each event. We see that the "strongest" event (in terms of the $\mathrm{ENPI}_{\mathrm{HP}}$ value) actually has an ENPI value that is not as low as it is at several other points during the winter. This is because the strongest event shows a sharp drop in the ENPI over a short period of time, which means that the $\mathrm{ENPI}_{\mathrm{HP}}$ value is actually lowest for that event. This particular winter only has a short period when the ENPI value is above the 0 threshold, and therefore only a short period that cannot be considered for La Niña events. However, that period is within the window of the strongest event, so in this case, those days would never have been chosen as an event even without the 0 threshold criterion.

As discussed in the introduction, subseasonal variability in El Niño-like or La Niña-like precipitation may be

\footnotetext{
${ }^{3}$ We choose 30 events to curtail the noise level while capturing the influence of the strongest events. Our results are broadly similar when we choose 15 or 60 events.
}

associated with the MJO or other phenomena that affect tropical convection on subseasonal scales. For example, a specific combination of certain phases of the MJO with the convection associated with a given El Niño or La Niña event may serve to suppress WP convection, or alternatively to enhance $\mathrm{CP}$ convection, in a manner that makes the overall convection look more El Niño-like or La Niñalike. To investigate the role of the MJO in determining our ENPI composites, we have calculated lag composites of the anomalous frequency for each MJO phase (with amplitude greater than 0.5), and for the "no MJO" case (with amplitude less than 0.5), for the +ENPI $\mathrm{HP}_{\mathrm{HP}}$ and $-\mathrm{ENPI}_{\mathrm{HP}}$ composites described above. The anomalous frequency is defined as the percentage of events in a given phase for the composite minus by the DJF climatological percentage for that phase. The result is seen in Fig. 3. We see that, although there is not an overwhelming signal for one or two favored MJO phases, there does appear to be a weak signal for an MJO wave in the $+\mathrm{ENPI}_{\mathrm{HP}}$ case, with an enhanced frequency of MJO phases 5 and 6 at negative lags, and phases 7 and 8 at positive lags. However, there is no overwhelming signal for any single particular MJO phase. A similar picture is seen in composites of RMM1 and RMM2 (cf. Wheeler and Hendon 2004; see also our Figs. S7 and S8), which show generally weak MJO amplitude near or below 0.5 at lag day 0 for both the + ENPI $_{\mathrm{HP}}$ and - ENPI $_{\mathrm{HP}}$ composites. The $+\mathrm{ENPI}_{\mathrm{HP}}$ composites show an MJO wave moving from phases 5 and 6 at negative lags through 7 and 8 at positive lags, while the - ENPI $_{\mathrm{HP}}$ composites are more equivocal.

For all calculations, ${ }^{4}$ statistical significance is determined based on performing a Monte Carlo simulation. For each lag day, we randomly select 30 days from

\footnotetext{
${ }^{4}$ We additionally perform composite calculations over North America for 2-m temperatures from ERA-Interim, as well as for CMAP precipitation over North America at positive lags. The resulting figures can be seen in Figs. S9 and S10.
} 
La Niña (2000-2001)
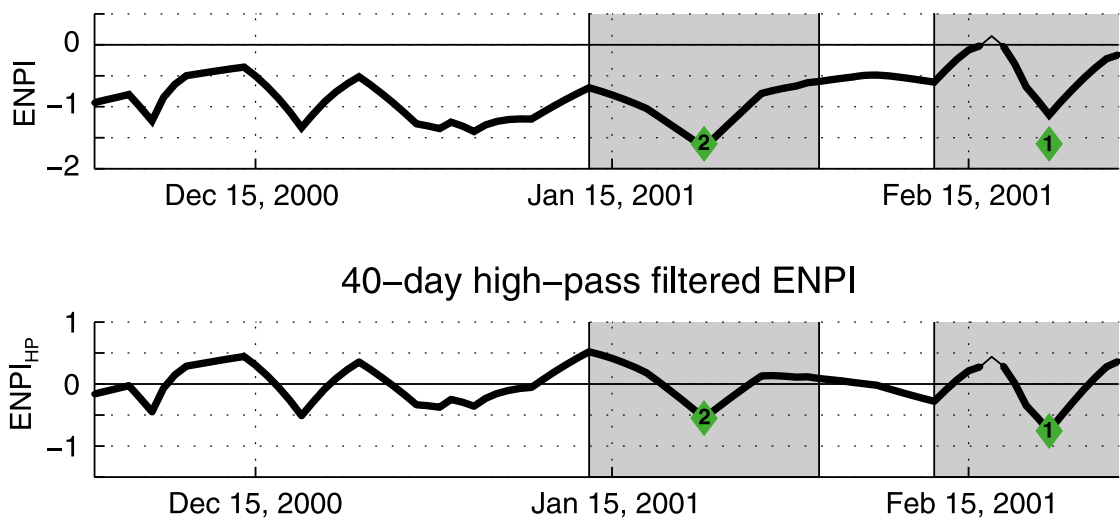

FIG. 2. (top) ENPI and (bottom) ENPI $\mathrm{H}_{\mathrm{HP}}$ values during DJF of 2000/01. Thick curves indicate times when the ENPI value is below 0 . Green diamonds labeled with a 1 and 2 indicate the first and second events chosen for this winter based on the method described in the text. Gray windows indicate the 21 days centered on each event during which future events cannot be chosen.

the pool of days from which the given lag day could be drawn. That is, for lag day 0 , we select 30 days from all DJF days; for lag day +30 , we select 30 days from all days between 31 December and $30 \mathrm{March}$, and so on.
We calculate composites using these randomly chosen days, and repeat the process until we have obtained 20000 simulated 30-day lag composites. This gives a distribution of randomly generated composite values

+ENPI Composite

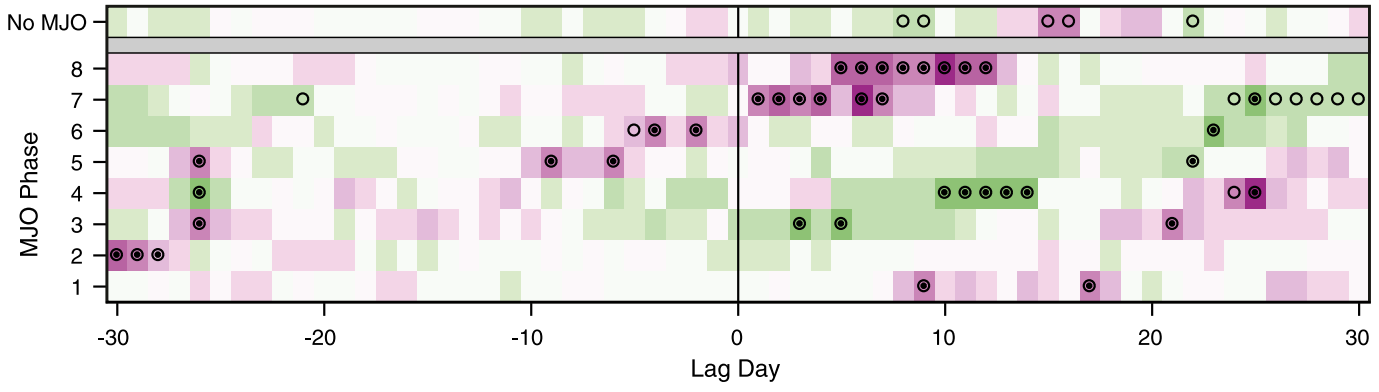

-ENPI Composite
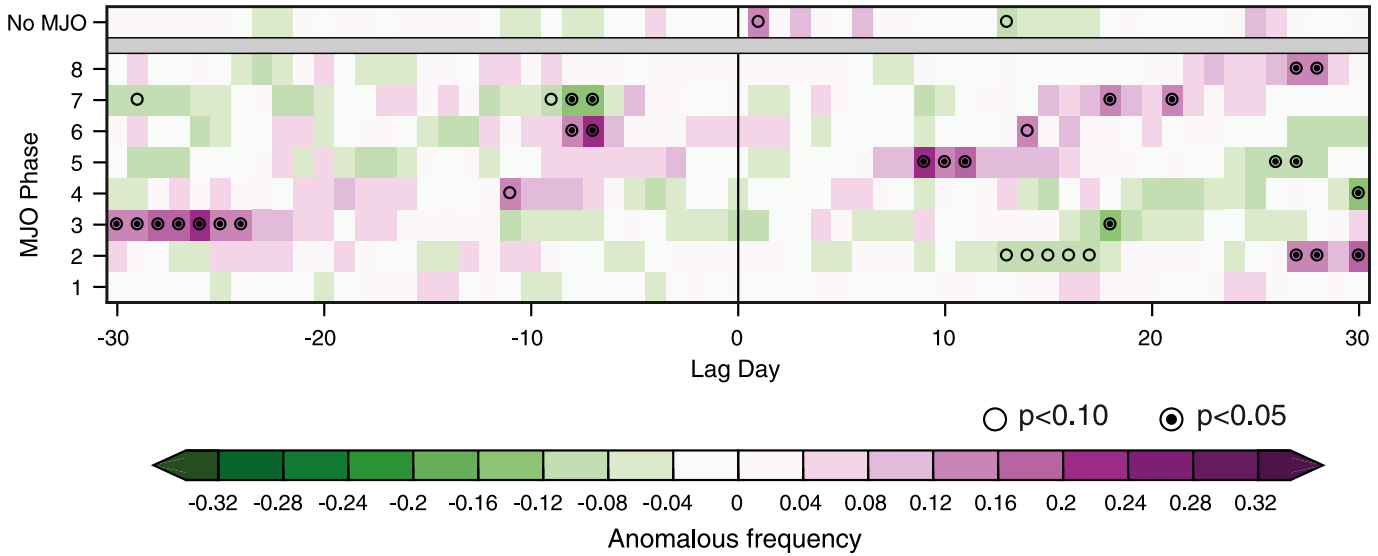

FIG. 3. Anomalous frequency from lag days -30 to +30 of each MJO phase with amplitude greater than 0.5 and for the "no MJO" case with any phase and amplitude less than 0.5 , for the (top) $30+\mathrm{ENPI}_{\mathrm{HP}}$ events and (bottom) $30-\mathrm{ENPI}_{\mathrm{HP}}$ events. Statistical significance calculated using a two-tailed Monte Carlo test is shown using open circles for $p<0.10$ and using circled dots for $p<0.05$. 
ENSO Precipitation Composites

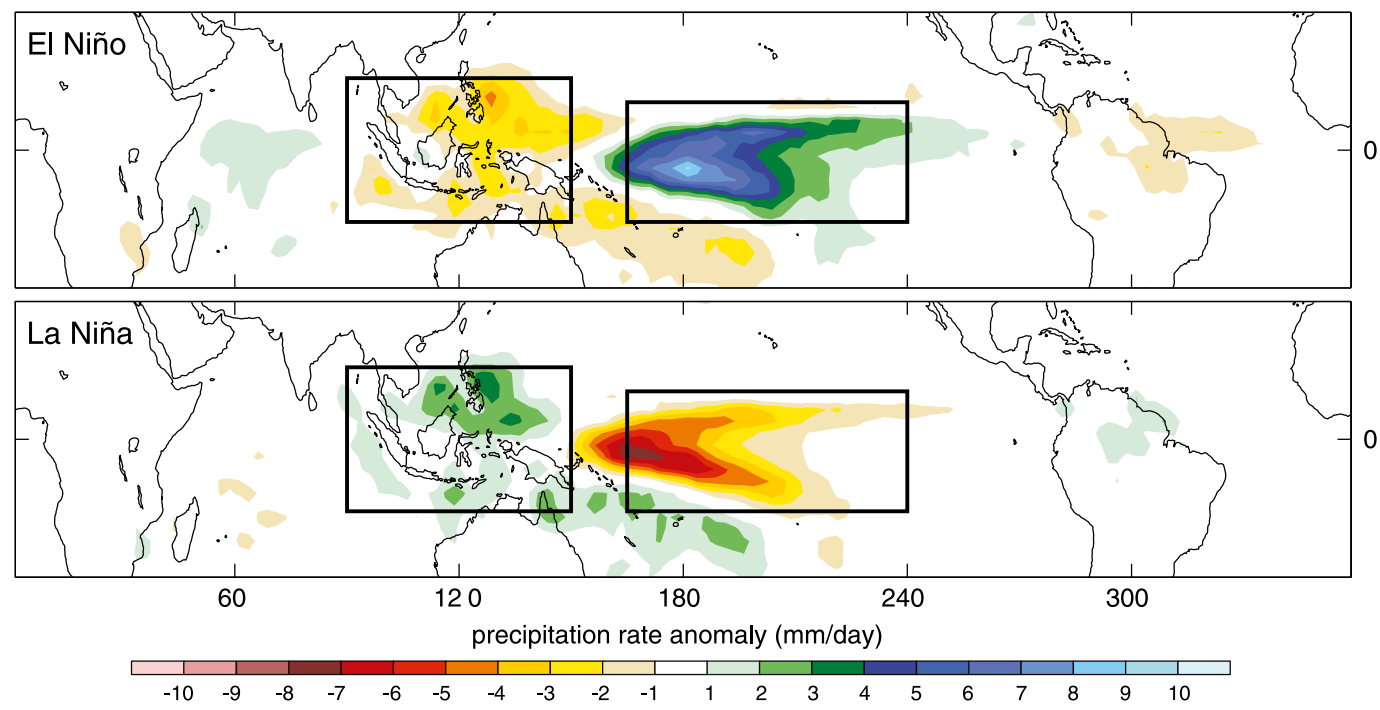

FIG. 4. Precipitation rate anomaly composites for DJF days during (top) El Niño and (bottom) La Niña. The boxes indicate the two regions used to calculate the ENPI. The western box is the WP domain, and the eastern box is the CP domain.

that we use to determine the $p$ values of the event-based lag composites.

\section{Analysis}

First, we briefly examine the precipitation and 300hPa geopotential height fields associated with El Niño and La Niña. A composite plot of precipitation during El Niño and La Niña months is shown in the top and bottom panel, respectively, of Fig. 4. The corresponding observed composite $300-\mathrm{hPa}$ geopotential height pattern is seen in Fig. 5. (The box in Fig. 5 corresponds to the domains over which composite geopotential height fields will be projected in later calculations; see section 2) The patterns in Figs. 4 and 5 are consistent with previous studies. For example, in Fig. 4, we see enhanced precipitation over the equatorial central $\mathrm{Pa}$ cific for El Niño and suppressed precipitation over the same region for La Niña. For Fig. 5, in the El Niño case, the response shows positive geopotential height anomalies in the subtropical Pacific, negative geopotential height anomalies over the central North Pacific, and positive geopotential height anomalies located over northern North America. The La Niña case shows mostly opposite anomalies, although the negative geopotential height anomalies over northern North America are substantially weaker.

Figure 6 shows lagged precipitation composites based on 30 positive and 30 negative ENPI events (see section 2 for details), in the left and right columns, respectively.
The rows correspond to lag days $-10,-7,-3$, and 0 from the peak of the events. Small plus symbols show grid points for which the precipitation anomaly is statistically significant at the two-tailed $p<0.05$ level. In the El Niño case, we see that the precipitation composite shows a weak El Niño-like signal at lag day -10, with weak enhanced precipitation over the central Pacific. The precipitation anomalies quickly intensify through lag day 0 , with very strong positive precipitation anomalies seen over the central Pacific by that day. A similar picture with anomalies of opposite sign is seen in the La Niña case, except with near neutral convection at lag day -10 evolving to moderately suppressed convection in the central Pacific by lag day 0 . These results generally show a rapid intensification of El Niño-like or La Niñalike precipitation conditions on a subseasonal time scale, suggesting that our method is able to effectively isolate the subseasonal geopotential height response to a subseasonal El Niño or La Niña precipitation signal.

Given this confirmation, we next investigate the composite height response to the precipitation fields for our chosen events. In Fig. 7, we show the 300-hPa geopotential height fields that follow the El Niño (left column) and La Niña (right column) precipitation composites seen in Fig. 6 . The rows here correspond to lag days $-2,+2,+6,+10$, and +14 from the peak of the events (which is defined using the precipitation fields). Small plus symbols correspond to grid points for which the geopotential height response is statistically significant at the two-tailed $p<0.05$ level. In the case of El Niño, we 


\section{ENSO Height Composites}

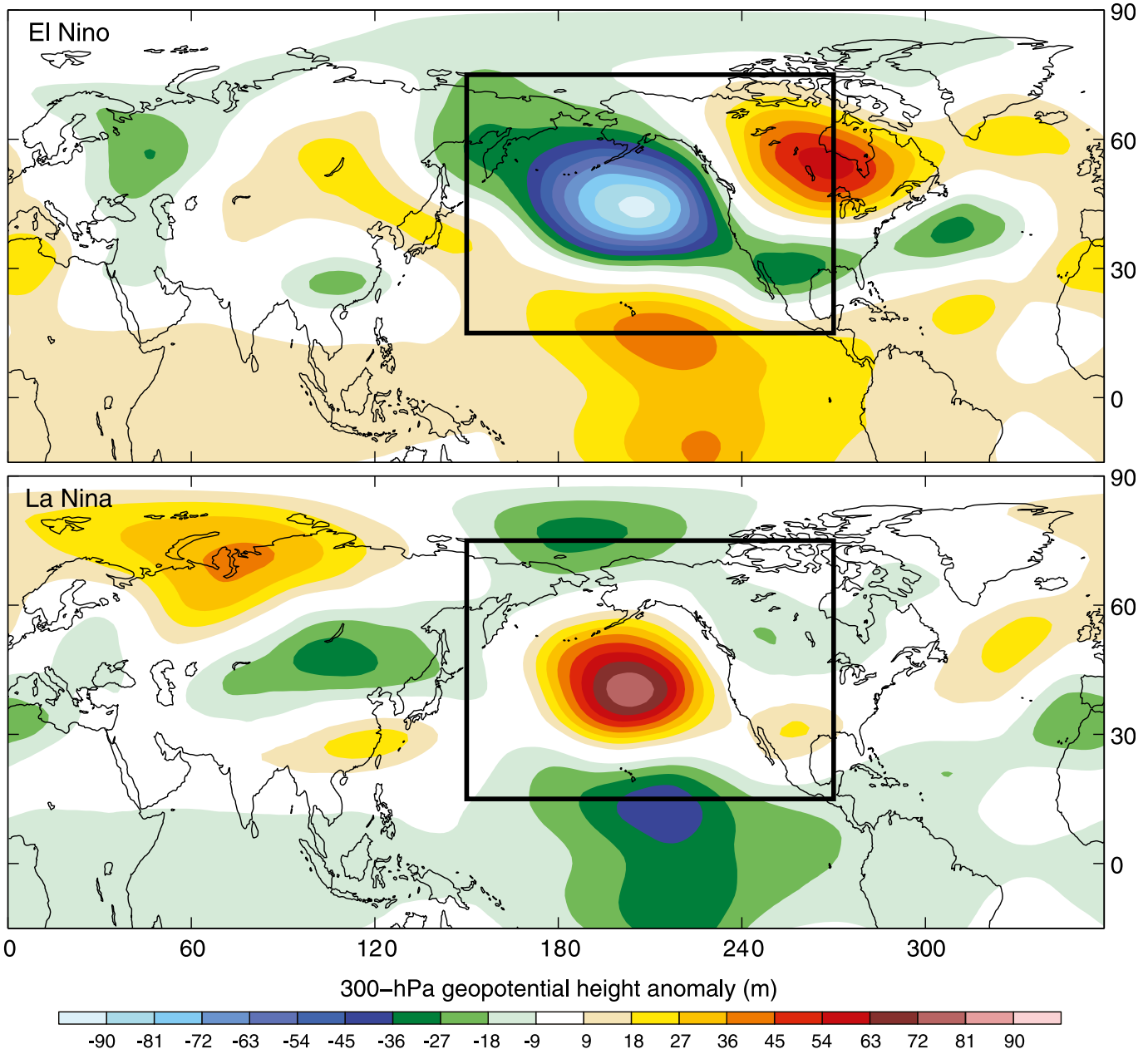

FIG. 5. The 300-hPa geopotential height anomaly composites for (top) El Niño and (bottom) La Niña. The boxes indicate the domain over which geopotential height anomalies are projected (see text).

see positive geopotential heights developing over the subtropical North Pacific as early as lag day -2 , and peaking at lag days +2 and +6 . Additionally, we see an initial ridge centered near $180^{\circ}$ longitude in the central North Pacific at lag day -2 , which gives way to a trough over that region by lag days $+6,+10$, and +14 . This is consistent with a geopotential height response at positive lags that resembles the canonical El Niño geopotential height response over the North Pacific, seen in Fig. 5. Interestingly, the pattern over North America does not match as well since the ridge that develops near the expected location around lag days +2 and +6 retrogrades westward, so that by later lags it is displaced somewhat to the west of where we would expect to see it. The La Niña case is largely similar over the North Pacific, but showing opposite-signed anomalies. One small difference is that the negative geopotential height anomalies over the subtropical North Pacific are weaker, which is not surprising, since the $\mathrm{CP}$ precipitation anomalies are also seen to be weaker in the La Niña case (cf. Fig. 6). The response in the La Niña case over North America is generally of the expected sign.

One interesting feature seen in Fig. 7 is the upstream anomalies over Eurasia at negative lags, especially in the El Niño-like composites. It may be that these upstream anomalies are partially responsible for the spatial pattern and amplitude of convection at lag day 0 or for the downstream height response. There are several previous studies investigating the relationship between the MJO and PNA that have shown similar upstream anomalies over Eurasia (e.g., Mori and Watanabe 2008; Franzke et al. 2011; Dai et al. 2017). In these studies, a wave train is seen over Eurasia for both PNA phases that closely resembles the wave train for the El Niño composites at lag day -2 in 


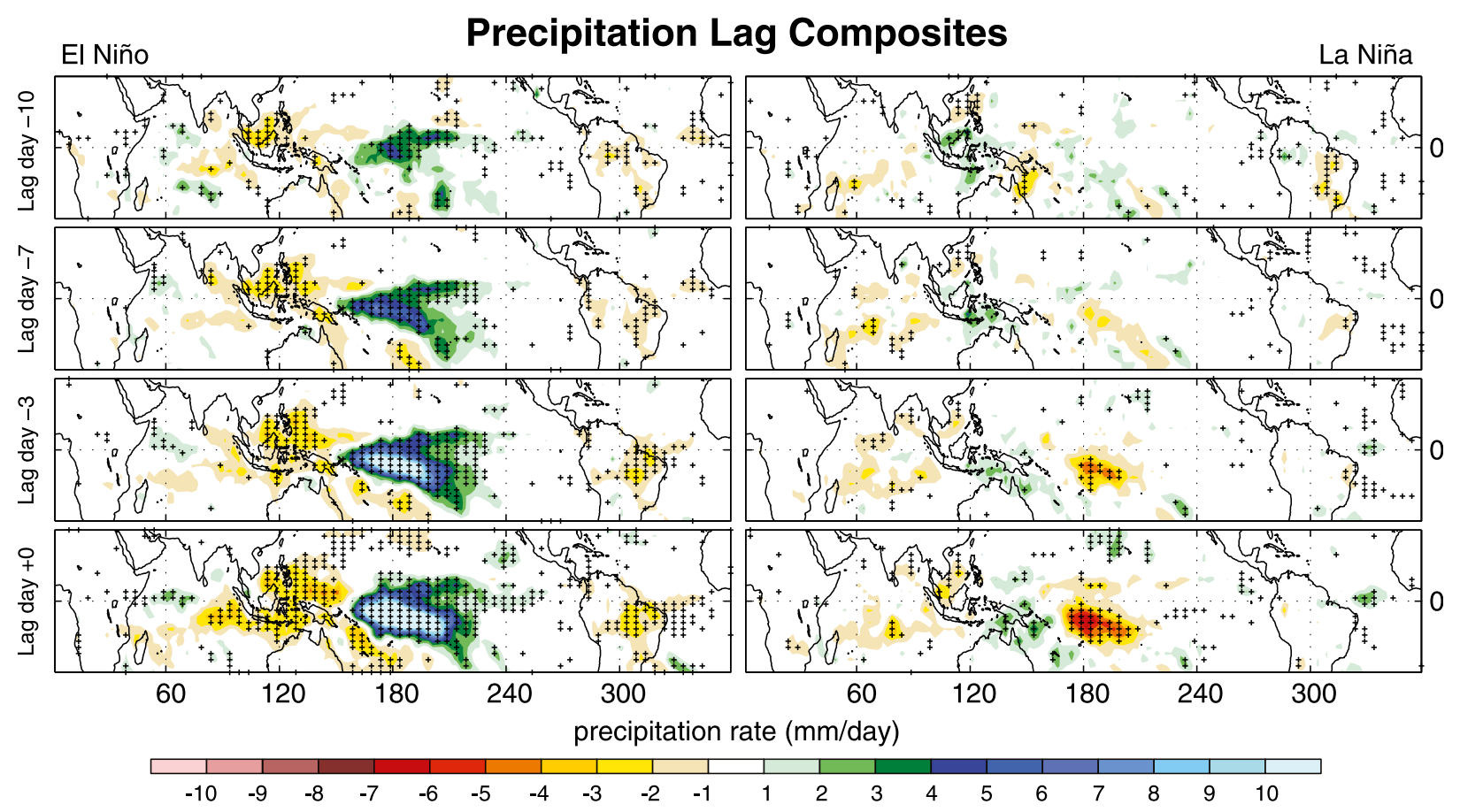

FIG. 6. Precipitation rate anomaly composites based on (left) El Niño and (right) La Niña events chosen using ENPI $\mathrm{HP}_{\mathrm{HP}}$, as described in the text. Lag days $-10,-7,-3$, and +0 are shown in rows $1-4$, respectively. Black markers indicate regions where the precipitation rate anomaly is significant at the $p<0.05$ level according to a two-tailed Monte Carlo simulation.

Fig. 7. It may be the case that there is a close connection on intraseasonal time scales between a Eurasian wave train, equatorial convection anomalies, and a height response over the North Pacific and North America.

To quantify the similarity between these composite patterns and the corresponding canonical pattern, we plot lagged composites of projection values for each case. We project each lag day's 300-hPa geopotential height field onto the corresponding El Niño or La Niña geopotential height field in Fig. 5, with the black box in that figure showing the domain over which the projections are calculated. For the El Niño case, we also plot the ENPI values, and for the La Niña case, we also plot the -ENPI values (ENPI values multiplied by -1 ). The results are shown in Fig. 8, with El Niño on the left, and La Niña on the right. Statistical significance is shown using lines colored based on the (one tailed) $p$ value. Additionally, white circles with black outlines indicate central times when the 9-day slope of the composite projection value, calculated using a least squares regression, is significant at the two-tailed $p<0.05$ level for the precipitation projections. Likewise, black circles with white outlines indicate central times when the 9-day slope is significant for the geopotential height projections.

We see that, as expected, there is a subseasonal peak in the ENPI values for both cases, centered on lag day 0 . The ENPI is generally positive from lag day -30 through lag day +30 , indicating that, on average, weak
El Niño like conditions persist during this composite of events. However, there does appear to be a significant peak in the geopotential height response at positive lags, centered from near lag day +5 to lag day +7 after the strong peak in El Niño-like precipitation. Other less significant peaks are seen at negative lags, which may be associated with the low-frequency positive ENPI, but we see that the most rapid increase in the geopotential height response occurs 5-10 days after the rapid increase in the ENPI. This circulation response time scale is consistent with the hypothesis of a subseasonal El Niñolike precipitation field driving a subseasonal El Niñolike geopotential height response.

In the La Niña case, we do not see a low-frequency negative ENPI signal. This result is interesting because Johnson and Kosaka (2016) found that subseasonal variability tends to be stronger during El Niño than during La Niña. Therefore, it may be that strongly El Niño-like convection over short time scales with a weak background El Niño occurs relatively more frequently than the La Niña counterpart. This may explain why the background appears to be more neutral for the -ENPI composites. We again see a strong, significant peak in the La Niña geopotential height response from lag days +5 to +7 . Interestingly, although the - ENPI $_{\mathrm{HP}}$ peaks at a smaller value than did the $\mathrm{ENPI}_{\mathrm{HP}}$ for El Niño, the geopotential height response peaks at a 
El Niño
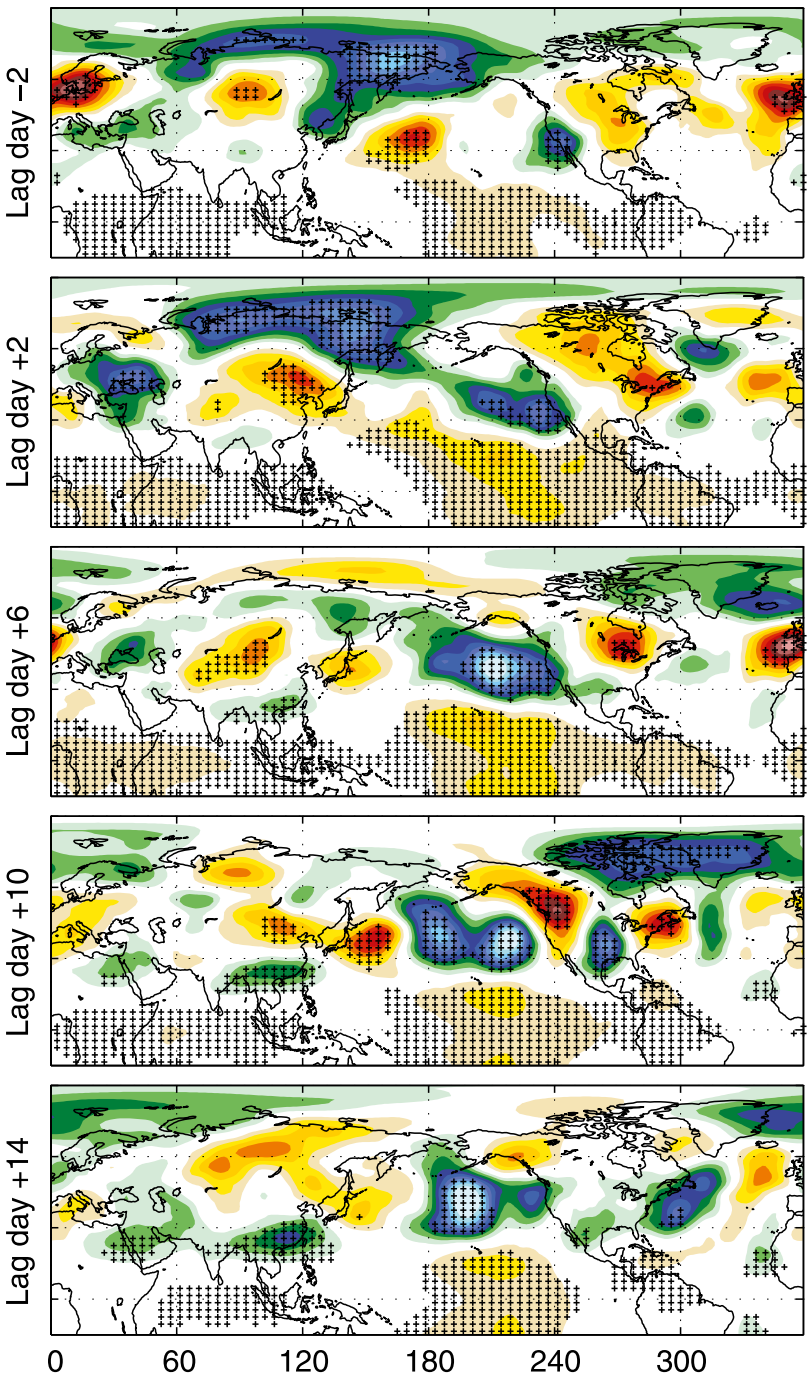

\section{0-hPa GPH lag composites}
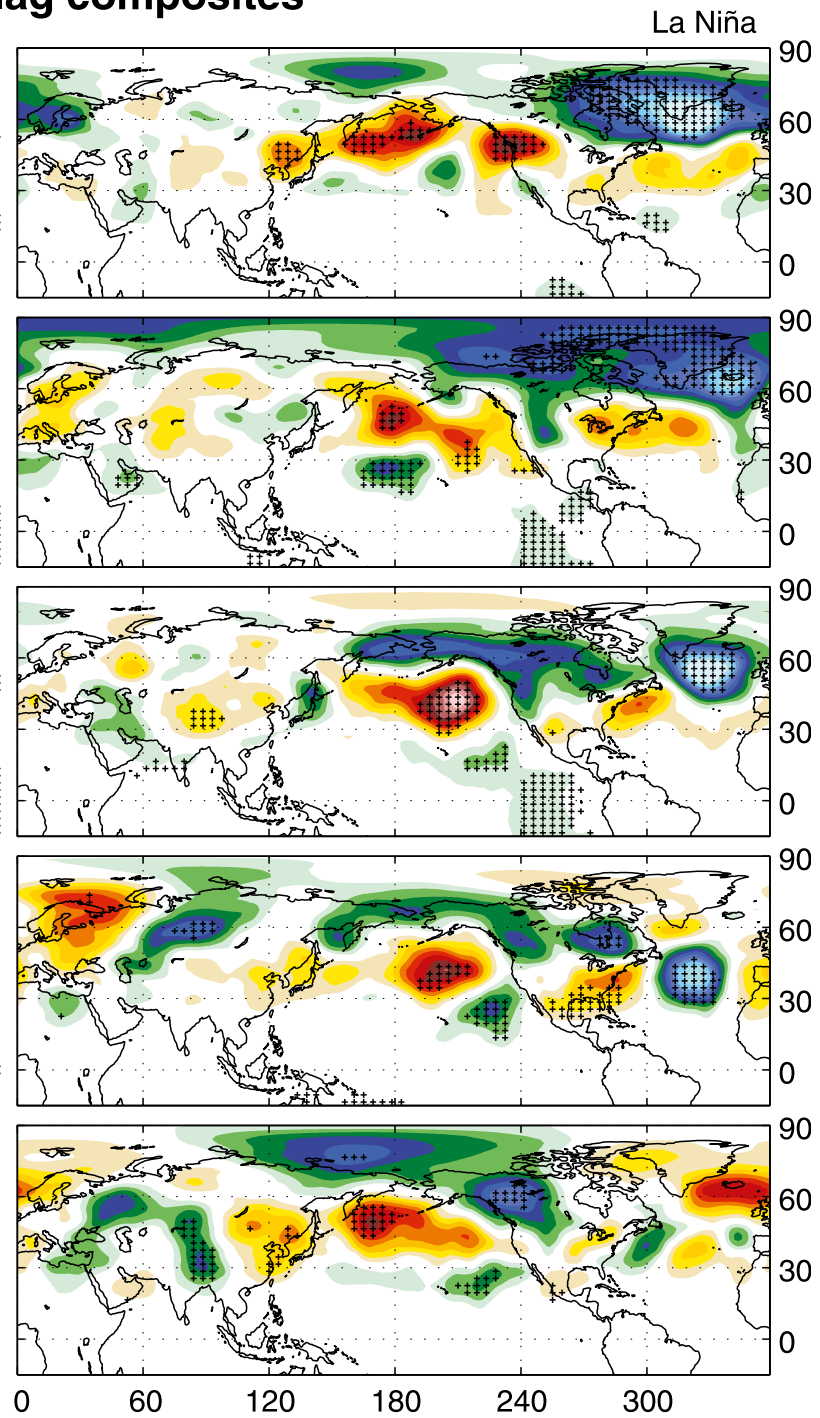

300-hPa geopotential height anomaly $(\mathrm{m})$

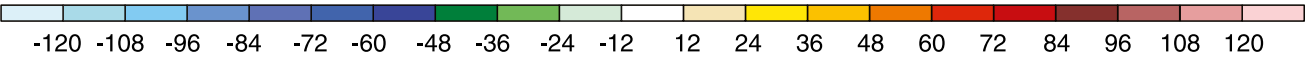

FIG. 7. The 300-hPa geopotential height anomaly composites based on (left) El Niño and (right) La Niña events chosen using ENPI ${ }_{\mathrm{HP}}$, as described in the text. Lag days $-2,+2,+6,+10$, and +14 are shown in rows $1-5$, respectively. Black markers indicate regions where the geopotential height anomaly is significant at the $p<0.05$ level according to a two-tailed Monte Carlo simulation.

higher value in the La Niña case. We do not have a hypothesis for why this is the case. Additionally, there is one period of statistically significant positive geopotential height projection values at negative lags, though this is more short-lived. We do not have an explanation for this peak, although it is perhaps associated with random variability in the extratropics, or is possibly associated with MJO activity. A clear, persistent positive slope is again seen in the geopotential height projection response about 5-10 days after the persistent positive slope in the -ENPI, consistent with the hypothesis of a subseasonal $\mathrm{La}$
Niña-like precipitation field driving a subseasonal La Niña-like geopotential height response.

\section{Conclusions}

In section 1, we posed four key questions. 1) Do there exist times when precipitation anomalies over the tropics become significantly more El Niño-like or La Niña-like over subseasonal time scales? 2) If so, do we see an associated El Niño-like or La Niña-like geopotential height response over the North Pacific and North America? 3) How 

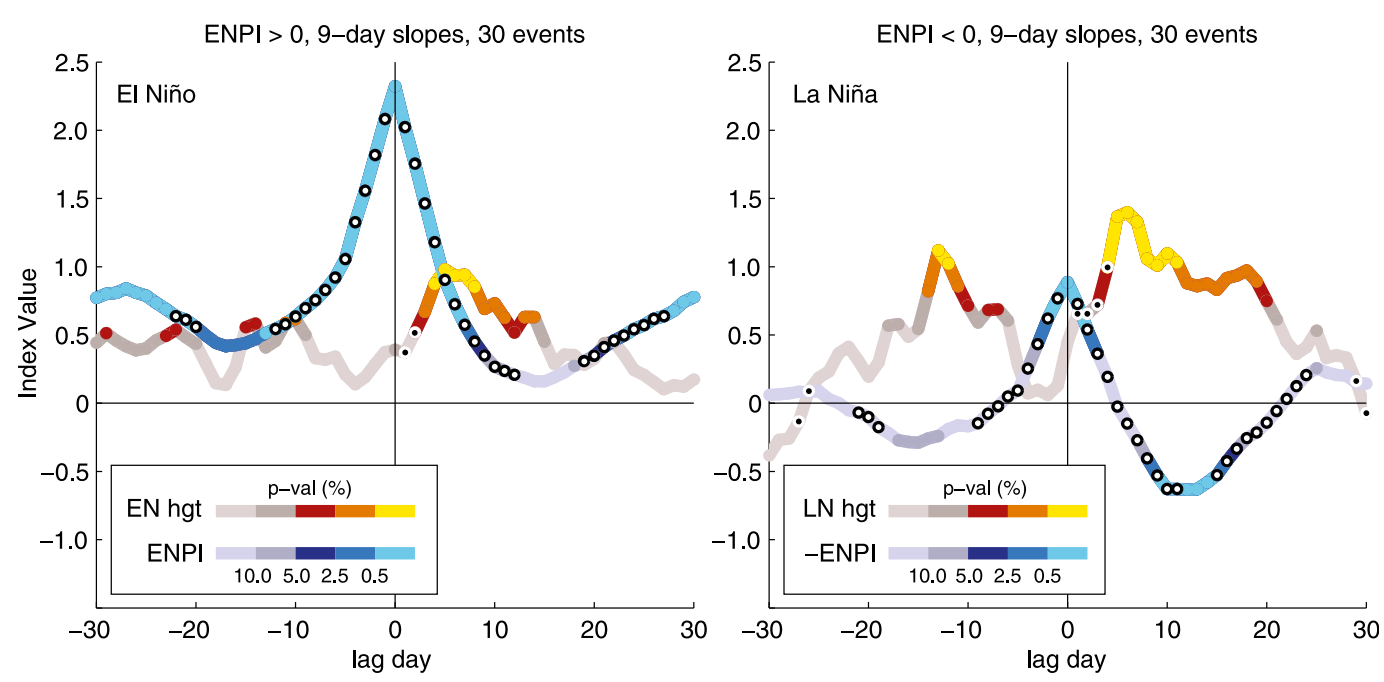

FIG. 8. Lag composite plots of ENPI values (cool colors) and 300-hPa geopotential height projections (warm colors) for the (left) El Niño and (right) La Niña events chosen using ENPI ${ }_{H P}$, as described in the text. The line color indicates the $p$ value based on a one-tailed Monte Carlo simulation (see legend). Black and white markers for a given lag day indicate times when the 9-day slope of the line centered on that day are significantly positive or negative using a two-tailed Monte Carlo simulation with $p<0.05$.

long after the tropical forcing does the extratropical response occur? 4) What does the subseasonal response to El Niño-like or La Niña-like convection imply about the seasonal response to El Niño or La Niña? To address these questions, we developed a daily index based on times when precipitation over the equatorial Pacific was dominated by anomalies in a key ENSO precipitation region. This index tends to match what one would expect based on SSTs in the Niño-3.4 region, but it varies with convection on subseasonal time scales. Composites of the index appear to be weakly tied to MJO events, in that there is a weak signal in the $+\mathrm{ENPI}_{\mathrm{HP}}$ composite for enhanced MJO activity in phases 5 and 6 at negative lags and phases 7 and 8 at positive lags.

Regarding question 1 , we found that there are times when, for several days, convection anomalies over the central equatorial Pacific are enhanced or suppressed in a manner consistent with the El Niño or La Niña composites, respectively. This subseasonal enhancement of the El Niño-like or La Niña-like convection may be in part modulated by the MJO. For question 2, we found that subseasonal peaks in El Niño-like or La Nina-like precipitation were followed by subseasonal peaks in the $\mathrm{El}$ Niño-like or La Niña-like geopotential height response over the North Pacific and North America. This response tends to peak about one week after the peak in precipitation, which addresses question 3 .

These results support the hypothesis that the extratropical response to ENSO occurs due to the same physical mechanisms that cause the extratropical response to any other phenomena that alter the convective precipitation field and large-scale circulation over the equatorial Pacific. That is, in the context of question 4 , the seasonal response to an El Niño event should begin within about 7 days of the initial forcing, and, because the seasonal response matches well with the subseasonal response, can likely be thought of as simply the mean response to the subseasonal forcing throughout the season. This is important, because, as in Johnson and Kosaka (2016), we purport that a better understanding of the response to any given El Niño or La Niña can come from taking into account the actual convective field over the equatorial Pacific at a particular time, which can provide useful information about the midlatitudes with a lead time of 1-2 weeks. Although the convective field at any given time can be strongly modulated by the underlying SSTs, ${ }^{5}$ other factors such as the MJO and equatorward propagating extratropical disturbances can affect the tropical circulation, and the sum of all of these varying impacts may give a much better indication of the corresponding extratropical response than would the SSTs alone.

Acknowledgments. This study is supported by National Science Foundation Grants AGS-1401220, AGS-1455577, and OPP-1723832; the U.S. Department of Energy, Office of Science, Biological and Environmental Research

\footnotetext{
${ }^{5}$ Oceanic convection is strongly modulated by SSTs beyond the convective threshold temperature, which is the SST beyond which conditional instability may exist. For example, Johnson and Kosaka (2016) show that precipitation varies linearly with SST beyond the convective threshold temperature, but does not vary with SST below that temperature.
} 
Program, Integrated Assessment Research Program, Grant DE-SC0016162; and Stanford University. We would also like to thank three anonymous reviewers, the European Centre for Medium-Range Weather Forecasts for providing us with the ERA-Interim reanalysis data that we used for the model climatology, and NOAA's Climate Prediction Center for providing the observed precipitation data.

\section{REFERENCES}

Alexander, M. A., I. Bladé, M. Newman, J. R. Lanzante, N. C. Lau, and J. D. Scott, 2002: The atmospheric bridge: The influence of ENSO teleconnections on air-sea interaction over the global oceans. J. Climate, 15, 2205-2231, https://doi.org/10.1175/ 1520-0442(2002)015<2205:TABTIO >2.0.CO;2.

Chiodi, A. M., and D. E. Harrison, 2013: El Niño impacts on seasonal U.S. atmospheric circulation, temperature, and precipitation anomalies: The OLR event perspective. J. Climate, 26, 822-837, https://doi.org/10.1175/JCLI-D-12-00097.1.

- , and 2015: Global seasonal precipitation anomalies robustly associated with El Niño and La Niña events-An OLR perspective. J. Climate, 28, 6133-6159, https://doi.org/10.1175/ JCLI-D-14-00387.1.

Dai, Y., S. B. Feldstein, B. Tan, and S. Lee, 2017: Formation mechanisms of the Pacific-North American teleconnection with and without its canonical tropical convection pattern. J. Climate, $\mathbf{3 0}$, 3139-3155, https://doi.org/10.1175/JCLI-D-16-0411.1.

Dee, D. P., and Coauthors, 2011: The ERA-Interim reanalysis: Configuration and performance of the data assimilation system. Quart. J. Roy. Meteor. Soc., 137, 553-597, https://doi.org/ 10.1002/qj.828.

Franzke, C., S. B. Feldstein, and S. Lee, 2011: Synoptic analysis of the Pacific-North American teleconnection pattern. Quart. J. Roy. Meteor. Soc., 137, 329-346, https://doi.org/10.1002/qj.768.

Gloersen, P., 1995: Modulation of hemispheric sea-ice cover by ENSO events. Nature, 373, 503-506, https://doi.org/10.1038/373503a0.

Goss, M., and S. B. Feldstein, 2017: Why do similar patterns of tropical convection yield extratropical circulation anomalies of opposite sign? J. Atmos. Sci., 74, 487-511, https://doi.org/ 10.1175/JAS-D-16-0067.1.

— and — 2018: Testing the sensitivity of the extratropical response to the location, amplitude, and propagation speed of tropical convection. J. Atmos. Sci., 75, 639-655, https://doi.org/ 10.1175/JAS-D-17-0132.1.

,$- \ldots$, and S. Lee, 2016: Stationary wave interference and its relation to tropical convection and Arctic warming. J. Climate, 29, 1369-1389, https://doi.org/10.1175/JCLI-D-15-0267.1.

Hanley, D. E., M. A. Bourassa, J. J. O'Brien, S. R. Smith, and E. R. Spade, 2003: A quantitative evaluation of ENSO indices. J. Climate, 16, 1249-1258, https://doi.org/10.1175/ 1520-0442(2003)16<1249:AQEOEI > 2.0.CO;2.

Hoskins, B. J., and D. J. Karoly, 1981: The steady linear response of a spherical atmosphere to thermal and orographic forcing. J. Atmos. Sci., 38, 1179-1196, https://doi.org/10.1175/ 1520-0469(1981)038<1179:TSLROA > 2.0.CO;2.

Jevrejeva, S., J. C. Moore, and A. Grinsted, 2003: Influence of the Arctic Oscillation and El Niño-Southern Oscillation (ENSO) on ice conditions in the Baltic Sea: The wavelet approach. J. Geophys. Res., 108, 4677, https://doi.org/10.1029/2003JD003417.
Johnson, N. C., and S. B. Feldstein, 2010: The continuum of North Pacific sea level pressure patterns: Intraseasonal, interannual, and interdecadal variability. J. Climate, 23, 851-867, https:// doi.org/10.1175/2009JCLI3099.1.

, and Y. Kosaka, 2016: The impact of eastern equatorial Pacific convection on the diversity of boreal winter El Niño teleconnection patterns. Climate Dyn., 47, 3737-3765, https://doi.org/ 10.1007/s00382-016-3039-1.

Julian, P. R., and R. M. Chervin, 1978: A study of the Southern Oscillation and Walker circulation phenomenon. Mon. Wea. Rev., 106, 1433-1451, https://doi.org/10.1175/1520-0493(1978)106<1433: ASOTSO $>2.0 . \mathrm{CO} ; 2$.

Lau, N.-C., 1997: Interactions between global SST anomalies and the midlatitude atmospheric circulation. Bull. Amer. Meteor. Soc., 78, 21-34, https://doi.org/10.1175/1520-0477(1997)078<0021: IBGSAA $>2.0 . \mathrm{CO} ; 2$.

Liu, J., J. A. Curry, and Y. Hu, 2004: Recent Arctic sea ice variability: Connections to the Arctic Oscillation and the ENSO. Geophys. Res. Lett., 31, L09211, https://doi.org/10.1029/2004GL019858.

Madden, R. A., and P. R. Julian, 1971: Detection of a 40-50 day oscillation in the zonal wind in the tropical Pacific. J. Atmos. Sci., 28, 702-708, https://doi.org/10.1175/1520-0469(1971)028<0702: DOADOI $>2.0 . \mathrm{CO} ; 2$.

Mori, M., and M. Watanabe, 2008: The growth and triggering mechanisms of the PNA: A MJO-PNA coherence. J. Meteor. Soc. Japan, 86, 213-236, https://doi.org/10.2151/jmsj.86.213.

Rasmusson, E. M., and J. M. Wallace, 1983: Meteorological aspects of the El Niño/Southern Oscillation. Science, 222, 1195-1202, https://doi.org/10.1126/science.222.4629.1195.

Ropelewski, C. F., and M. S. Halpert, 1986: North American precipitation and temperature patterns associated with the El Niño/Southern Oscillation (ENSO). Mon. Wea. Rev., 114, 2352-2362, https://doi.org/10.1175/1520-0493(1986)114<2352: NAPATP $>2.0 . \mathrm{CO} ; 2$.

Trenberth, K. E., 1997: The definition of El Niño. Bull. Amer. Meteor. Soc., 78, 2771-2777, https://doi.org/10.1175/ 1520-0477(1997)078<2771:TDOENO > 2.0.CO;2.

—, G. W. Branstator, D. Karoly, A. Kumar, N.-C. Lau, and C. Ropelewski, 1998: Progress during TOGA in understanding and modeling global teleconnections associated with tropical sea surface temperatures. J. Geophys. Res., 103, 14 291-14 324, https://doi.org/10.1029/97JC01444.

Wheeler, M. C., and H. H. Hendon, 2004: An all-season real-time multivariate MJO index: Development of an index for monitoring and prediction. Mon. Wea. Rev., 132, 1917-1932, https:// doi.org/10.1175/1520-0493(2004)132<1917:AARMMI>2.0.CO;2.

Xie, P., and P. A. Arkin, 1997: Global precipitation: A 17-year monthly analysis based on gauge observations, satellite estimates, and numerical model outputs. Bull. Amer. Meteor. Soc., 78, 2539-2558, https://doi.org/10.1175/1520-0477(1997)078<2539: GPAYMA $>2.0 . \mathrm{CO} ; 2$

Yoo, C., S. Lee, and S. B. Feldstein, 2012a: Mechanisms of extratropical surface air temperature change in response to the Madden-Julian oscillation. J. Climate, 25, 5777-5790, https:// doi.org/10.1175/JCLI-D-11-00566.1.

, — tropical heating in an idealized GCM. J. Atmos. Sci., 69, 2379-2393, https://doi.org/10.1175/JAS-D-11-0261.1.

Zhang, Y., J. M. Wallace, and N. Iwasaka, 1996: Is climate variability over the North Pacific a linear response to ENSO? J. Climate, 9, 1468-1478, https://doi.org/10.1175/1520-0442(1996)009<1468: ICVOTN $>2.0 . \mathrm{CO} ; 2$. 